Mills, S.W. (2003) Reggae for Standards-Based Music Learning. General Music Today, 17(1): 11-17. (Fall 2003)

Published by Sage (ISSN: 1931-3756). DOI: 10.1177/10483713030170010104

\title{
Reggae for Standards-Based Music Learning
}

Susan W. Mills

When you hear reggae music you might imagine scenes from a Caribbean beach or the feeling of balmy ocean breezes. Reggae music usually sounds easygoing and gentle with a cheerful, upbeat rhythm. Reggae dancers move with the flow of the songs, as though they are just walking down the beach. This seemingly cheerful music is noteworthy for music educators, because there can be great value in the study of "folk-turned-pop" music. Folk music reflects a culture's language, ethnicity, values, and important themes.

Four of the National Standards for Music Education have achievement standards for $\mathrm{K}-4$ that refer to the music of diverse cultures. In Content Standards 8 and 9, students learn about the role and relationship of music to culture, meaning both the history and the development of cultural expression (Consortium of National Arts Education Associations 1994). 
Multicultural music lessons should focus on the elements of music, within the cultural contexts addressed in Standards 8 and 9, for the experience to hold meaning for students. In Jamaica, folk music traditions developed into commercially viable popular music. With careful selection, students will respond positively to the content and enjoy the inclusion of Jamaican folk and pop repertoire in their music studies, while meeting national standards in music education.

\section{UNDERSTANDING REGGAE MUSIC IN RELATION TO HISTORY AND CULTURE}

he lyrics of reggae music have traditionally featured political, social, or even religious themes. Like many folk-turned-pop styles of contemporary music, the messages and some of the values have changed over the years. Early reggae from the 1960 s reflected the oppression of the Jamaicans in their own island communities. They often turned to religion as a release from poverty and poor social conditions. Folk music in North America in the 1960s also reflected people's discontent with social conditions and political policies.

During this time, some well-known reggae songs, such as "I Shot the Sheriff" (on the Legend CD, see Resources), made the American pop charts and drew the attention of popular musicians throughout Europe and Africa. The lyrics of these songs lamented the social conditions in Jamaica and told of negative consequences for the people involved. Sometimes the messages were very subtly stated so that songwriters could record and perform their music without censorship or fear of arrest. The song "By the Rivers of Babylon" tells of the Israelites' longing for Zion during the biblical era of enslavement, also discreetly telling of Jamaicans' longing for self-determination and better lives.

Many popular reggae songs accessible for students' music experiences are derived from familiar songs in the American folk and recording of Bob Marley and the Wailers on 
the Studio One label includes the songs "This Train" and "Sinner Man" alongside songs about reggae rhythms and music such as "Rockin' Steady."

An introductory experience to orient students to the sound of reggae rhythms might be to play examples of these familiar spirituals from a conventional recording (or sing them in class), and then have students compare these versions with reggae versions. Although many musical elements might be mentioned, it is the rhythm of reggae music that stands out as the unifying and identifiable feature of the musical style.

Reggae rhythms originated in a Jamaican style of folk music called ska, with some influence from rhythm and blues, spirituals, and rock. Some commonly used reggae rhythm patterns are related to West African ritual drumming. All of these reflect a blend of African, African-American, and Jamaican influences.

\section{REGGAE MUSIC EDUCATION RESOURCES}

In recent years, Jamaican (and nonJamaican) reggae musicians have used more positive themes in reggae music. The music is widely considered a treasured cultural export for Jamaica, so musicians who still desire progress for their island nation have begun focusing on themes of hopefulness, faith, and love. For elementary children, reggae songs such as "Give a Little Love," "One Love," or "Three Little Birds," all written by Bob Marley, can be sung and enjoyed for their optimism and cheerful lyrics. Putumayo World Music includes a Cedella Marley Booker and Taj Mahal version of "Three Little Birds" in their World Music Playground series. The educational series is an excellent resource for teaching folk music from world cultures and includes a map, passport, games, and activity worksheets for students. Background information on each of the cultures is provided along with 
instructions for learning about both the music and the culture.

The recording features Cedella Marley Booker (mother of the late Bob Marley) singing the lead vocal and using a lower register than most music education models. As teachers use the materials they can guide children to discuss the low register and the differences in the sounds from their typical singing voices. From a trained musician's perspective, folk musicians often break the rules about singing in proper registers. Nonetheless, Booker's son Bob is widely considered the "King of Reggae," and she often sang to her son during his childhood, so this version of the song can be an introductory experience for children.

Bob Marley is known for his development of popular reggae music and for his leadership role in Rastafarianism, a religious philosophy espoused by many Jamaicans. Although there is a negative association of Rastafarianism with ritual drug use that may be inappropriate content for music classes, the positive association of Bob Marley with the expression of freedom is a well-known feature of Jamaican culture. Teachers may want to discuss drug abuse as students learn more about Marley and reggae music. They should guide their students with the same care that an educator would use in recommending followup activities about jazz musicians or performers in any other musical style and their association with drugs. With reggae, more emphasis could be placed on the positive associations. For example, information about Bob Marley and his freedom movement can easily be found on the Internet (though some Web sites are not appropriate for elementary students). Guide students to discoveries about the music and the man by searching for terms such as "Jamaican music" to keep musical concepts at the forefront of the discussion.

Reggae music is now a part of mainstream popular music in the U.S. and around the world, and study of this musical style does not need to be omitted because of possible 
associations with Rastafarian drug practices. For example, there is an attraction called "Bob Marley-A Tribute to Freedom" at Universal Studios' CityPark in Orlando, Florida. In addition to historical information about Marley, the attraction includes samples of Jamaican food, information about Jamaican culture and live reggae musical productions. This is an example of ways that a musician and his culture can interest people in a positive way.

Cedella Marley Booker's strong feelings about sharing music with children and with all people represent a positive message about the intrinsic value music holds. Teachers can select resources that emphasize the value of music as a means of cultural expression. Audio interviews with Booker and more information on her life, reggae, and Jamaican history are available on the Web sites listed in the resources.

\section{USING REGGAE AS PART OF A VARIED REPERTOIRE OF MUSIC}

The song "By the Rivers of Babylon" is commonly found in music education materials and is now standard Caribbean repertoire. The book Pandemonium Rules! Orff Instrument Arrangements of Steel Band Music includes a simple instrumental arrangement of the song and says that it originated as a spiritual. Although this book is intended for use by Orff-Schulwerk ensembles, it includes music and lyrics for all of the songs, making it practical for other music lessons that focus on singing. "By the Rivers of Babylon" became popular when it was included on the soundtrack of the movie The Harder They Come. The movie depicts a Jamaican youth struggling with poverty and the lack of opportunity in the city. The song is a natural springboard for discussion about the ways music reflects our feelings and ideas about life.

World Music Drumming curriculum includes the song "By the Waters of Babylon," from the island of Bequia (200 miles off the 
northeast coast of Venezuela), along with many other Latin American musical selections. For older elementary or secondary school students, this resource could be valuable in comparing the elements of Jamaican reggae music to similar elements in nearby or related cultures. For example, students can be asked, "The title of the 'Babylon' song is slightly different from the Jamaican version. What variations can you find in the written (or sung) music?" Students will be listening to, analyzing, and describing music (National Standard 6). The curriculum includes a master student edition, from which sheet music and activities can be copied, as well as an instructional video for teachers and students. This resource is well suited for students who may be less than enthusiastic about singing as their sole experience in a music lesson. A major educational advantage is that the curriculum employs the reading of simple ostinato rhythms and layers them with other instruments. Readiness for reading multiple staves of music (National Standard 5) could be achieved while singing and playing some well-selected reggae and Latin multicultural music.

\section{CREATING REGGAE MUSIC IN CLASS}

In a singing classroom, the introduction of recorded reggae music is recommended so that students can experience the cheerful, breezy feeling of the music. CDs such as Legend by Bob Marley and the Wailers and The Harder They Come by Jimmy Cliff both contain politically charged selections as well as optimistic, cheerful numbers. The song "Give a Little Love," credited to Marley's son Ziggy, appears in a music textbook called Making Music: Grade 6. After listening to the recording, students can study three or four rhythm patterns and play them on body percussion or hand-held percussion instruments. This sequence works well, especially if students can then apply these rhythms to other reggae songs or take a folk song and create a reggae sound by adding the rhythms. Students will be arranging music within specified guidelines (National Standard 
4) and singing a varied repertoire of music (National Standard 1).

Another music text, Share the Music: Grade 5, features the four-phrase song "Everybody Loves Saturday Night," listed as a West African song. This book includes directions for a dance, and the accompanying recording has a lively accompaniment. The tempo is fast, but the sequencing of the lesson includes movement, a focus on solfège with Kodály hand signs, and notation.

To practice reggae rhythms, teachers may try adding in another layer for this lesson or for any reggae song selected, by using the reggae rhythm patterns backbeat (see figure 1), rock, or rock steady (see figure 2), and walking down the beach (see figure 3). Once students can perform the rhythms, they will enjoy experimenting with songs that may lend themselves to a reggae experience.

\section{TEACHING STRATEGY}

1. Divide the students into three groups and place them so that they are able to see the other groups. This creates a quick visual reinforcement of the differences in the three rhythm patterns.

2. Teach Group 1 the back beat pattern. It can be played on rhythm sticks or with hand taps or claps. (The back beat is often played by a guitar or keyboard in contemporary reggae recordings, so consider this step readiness if keyboards, guitars, or autoharps will play the chords in a later lesson for the selected song.) The back beat pattern is most effective with an accent on the first eighth note in each pair.

3. Group 2 can play the rock beat using hand drums, body rhythms (patsching), or bouncing tennis balls. The tennis balls are more challenging than hand drums, and students get a kick out of practicing the coordination skills needed to maintain the steady tempo. The rock pattern is 
often called rock steady in music texts because a variation of reggae music is also named rock steady music.

4. Give Group 3 some room to move and assign the walking down the beach pattern. The students should step on each quarter note beat as though they are walking, shifting their weight with each step as they stroll. Have them chant aloud at first, then just move silently. The movement is a fun way to internalize each steady quarter note beat.

Students will enjoy the movement, the addition of tennis balls, and the idea of taking a familiar song and "making it reggae." The tennis balls are not required, since they do not represent authentic Jamaican instruments.

Because they are quiet compared to the sound of several drums, students can practice maintaining the rock beat while they practice hearing the complementary rhythms as they wait their turn to play drums. The teacher can assess students' mastery of the rhythms as they change groups and apply the patterns to new songs.

Music educators will need recordings of reggae music to explore the musical style fully with their students. Lessons can begin with an introductory experience such as listening and comparing reggae with nonreggae versions of songs mentioned earlier in this article. Then, using the World Music Drumming curriculum or (if more appropriate due to grade level of students) one of the elementary music text versions, the teacher may teach the class one piece of reggae music as an ensemble experience. The class may analyze the ensemble music for its social content, noting the relationship of the music to the social history of Jamaica. "One Love" sends a message of global unity, for instance, while "Rivers of Babylon" refers to the difficulty of displacement in a foreign land. The role of music and musicians can be highlighted by examining the powerful leadership role that Bob Marley played, the Internet interview with his mother, and the tributes paid to Marley and his music at venues such as the 
Universal Studios' CityWalk.

Reggae musicians are not just from

Jamaica anymore, and reggae lovers represent

many countries in the world. The reggae

music style is now part of global popular

culture. The tradition of reggae music comes

from an interesting, yet difficult history for

Jamaicans. This cultural treasure can be an

enjoyable and educational experience in the music classroom as students include reggae rhythms in their music studies and create their own sounds of hope and faith for the future.

\section{RESOURCES}

\section{Recordings}

Bob Marley and the Wailers. One love. Studio One sound recording, 1965.

Cliff, Jimmy. The harder they come. Mango, original soundtrack CD, 1972.

Marley, Bob. Legend, Universal CD, 1990.

\section{Curriculum Materials}

Garofalo, Reebee. 2002. Rockin out: Popular music in the USA. $2 \mathrm{~d}$ ed. Upper Saddle River, NJ: Prentice Hall.

McGraw Hill. 2000. Share the music: Grade 5. New York: McGraw Hill. Music textbook and recording.

Teason, Deborah Fischer, and Gage Averill with Pandemonium Steel Band. 1994. For Orff instruments! Pandemonium rules! Orff instrument arrangements of steel band music. Danbury, CT: World Music Press. Book and recording.

Schmid, Will. 1998. World music drumming: $A$ cross-cultural curriculum. Milwaukee: Hal Leonard. Student and teacher books and video. 
Silver Burdett. 2000. Making music: Grade 6.

Glenview, IL: Scott Foresman. Music

textbook and recording.

Putumayo World Music. 2001. World

playground multicultural curriculum. New York:

Putumayo World Music. Book and recording.

\section{Web Sites}

http://debate.uvm.edu/dreadlibrary/dreadlib

rary.html. This website features scholarly

papers on the subject of reggae and ska music

in the context of Jamaican history.

http://www.classical-reggaeinterviews.

org/cb-int.htm. Cedella Marley

Booker interviews about Bob Marley.

\section{REFERENCE}

Consortium of National Arts Education

Associations. 1994. National Standards for Arts

Education. Reston, VA: MENC: The National

Association for Music Education. 
Figure 1

\section{Back Beat Pattern}

Rhythm Sticks, Hand Clap

Autoharp, Guitar, Keys

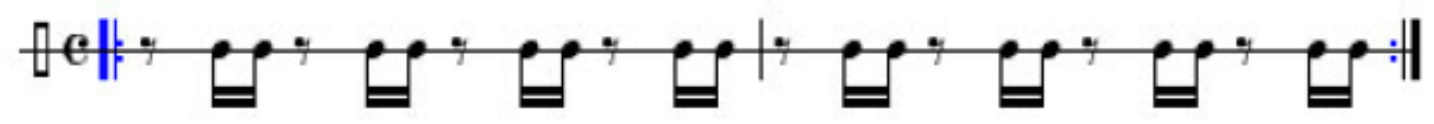

Figure 2

Tambourine

\section{2\&4 Rock Beat (Rock Steady)}

Hand Drum

Tennis Balls

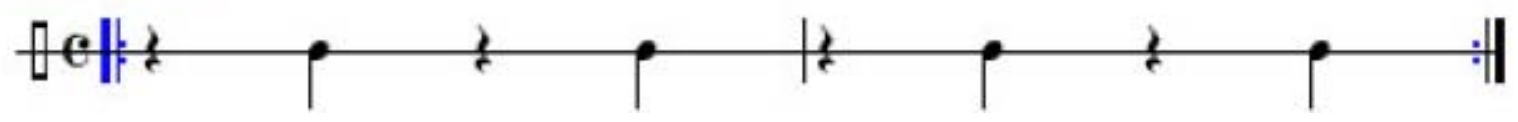


Figure 3

\section{Walking Down the Beach Pattern}

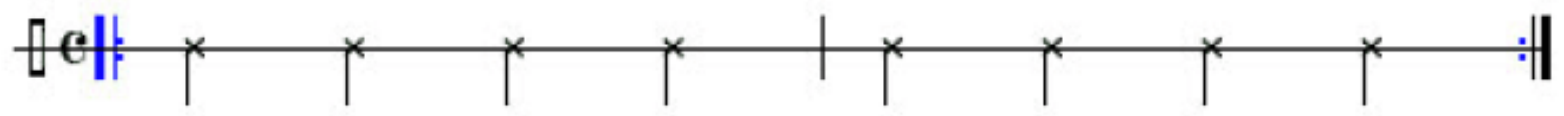

Whing Down (the)Beach Just Wiking Down (the)Beach Just 